\title{
Gender and Sports: An Anthropological Overview
}

\author{
Abhijit Das* \\ Department of Anthropology, India \\ *Corresponding author: Abhijit Das, Associate Professor, Department of Anthropology, Barasat, Kolkata, India 700126
}

Submission: 眥 January 02, 2018; Published: 眥 March 13, 2018

\begin{abstract}
Sport behaviour in any situation is culturally defined. The anthropological study of sports can provide a viewpoint of human culture in real sense of the word. Sports as a recreational aspect of culture hold a variety of different meanings across culture. It has been observed that, sports have emerged as a primary area of controversy about men's and women's roles. It has also widely argued that women's sport has changed a little in the present century. Anthropologists considered this issue that sports are the areas where gender inequalities are strongly evident. The present study is the preliminary observations on the relationship between sports and gender along with how the participation in sports can be invigorating and personally empowering experience for women. It finally throws light on how sports are one of the most important issues in gender inequality.
\end{abstract}

Keywords: Sports; Gender; Inequality; Society; Culture; Globalization

\section{Preamble}

At the very least, in any human society, there is some difference between the roles of men and women. What every culture does is to give meaning to these differences by explaining them and specifying what is to be done about them. Every culture as well specifies how the kinds of people resulting from the differences should relate to one another and to the world at large. Since each culture does this is in its own way, there is tremendous variation from one society to another. Anthropologists use the term 'gender' to refer to the cultural elaborations and meanings assigned to the biological differentiation between the sexes. Thus, though one's sex is biologically determined, one's sexual identity or gender is culturally constructed [1]. Gender is the term for the cultural and social classification of masculine and feminine. So, gender is the social, cultural, and psychological constructs that different societies superimpose on the biological differences of sex [2]. Every culture recognizes distinctions between male and female, but cultures differ in the meanings attached to these categories, the supposed sources of the differences between them, and the relationship of these categories to other cultural and social factors. Therefore, gender refers to culturally constructed and learned behaviours, ideas and roles attributed to males and females, or sometimes a blended, or "third" gender [3].

The current anthropological approach to gender emphasizes the central role of gender relations as a basic building block of culture and society. Gender is central to social relations of power, individual and group identities, the formation of kinship and other groups, and meaning and value. The area focusing on the cultural construction of gender emphasizes the different ways cultures think about, distinguish, and symbolize gender [4]. It is also worth mentioning in this context that, gender issues are the part and parcel of different aspects of socio-cultural system like, economy, politics, religion, education, recreation (sports).

Anthropological Significance of Sports, Society, and Culture

Sports are important parts of culture which differs from time and space. How they existed, defined, organized, institutionalized, and integrated into socio-cultural life varies from one society to another. This means that, to understand sports, we must view them as socio-cultural constructions created in particular social and cultural contexts. Anthropologists study sports in culture because play, games and sports are important and inseparable parts of everyday life around the world. Anthropology is the holistic study of man in time and space. Cultural anthropology is the study of social and cultural life or system, including all forms of social interactions and relationships. It is the study of contemporary people and their cultures. It considers variations and similarities across cultures, and how cultures change over time. Therefore, the study of human society and culture is known as cultural anthropology. It is the study of human thought, meaning, and behaviour that is learned, and is typical of groups of people living in society $[3,4]$. Hence, here is the first and foremost justification of considering sporting behaviour, being a cultural one in society in cultural anthropology. 
Cultural anthropologists study sports as they are aspect of culture and are ubiquitous in culture. Sports are part of culture and society, like music, dance and art form. They look at sports in terms of their socio-cultural existence, role, and importance in people's lives and their connections to ideology and major spheres Like, economic, political, religious, educational, and so on) of sociocultural life. Study as well as research in the anthropology of sports helps us to understand sports as social and cultural constructions created by people for particular purposes under the purview of leisure time recreational aspect of culture in contemporary society. Therefore, it is impossible to fully understand contemporary society and culture without acknowledging the place of sports as an integrated cultural trait. We inhabit a world in which sport is an international cultural phenomenon. It is important for politicians and world leaders to be associated with sports personalities and the reverse cases are also true in the present day. It contributes to the economy; some of the most visible international spectacles are associated with sporting events world over; it is part of the social and cultural fabric of different localities, regions, and nations; its transformative potential remains evident in some of the poorest areas of the world; it is important to the media industry and the tourism industry; and it is regularly associated with social problems and other important as well as relevant issues like gender, health, crime, violence, ethnicity, social inequality, labor migration, economic and social regeneration, and poverty [5]. Moreover, if we analyze the levels of sports, culture and society in anthropological domain, it traditionally refers to values, rituals, ceremonies, and way of life characteristic of a given society as well as group and the place of sport within that way of life. Like the concept of society, the notion of culture is widely used in the anthropological, sociological, and historical study of sports. It has traditionally encouraged the scholars and students to consider the meanings, symbols, rituals, and power relations at play within any particular cultural setting.

\section{Sports: Definitions and Paradigms - A Brief Outline}

Although definitions of sports vary, those who offer definitions tend to emphasize that sports are institutionalized competitive activities that involve rigorous physical exertion or the use of relatively complex physical skills by participants motivated by internal and external rewards [6]. Sports is a human activity, usually associated with a degree of physical exertion, in which skill is accomplished in performance or contest, and for which there is either a competitive outcome (winner, loser, or position), a measureable achievement or some further perceived benefit (health, fitness, pleasure/fun) [5]. In attempting to define and classify sports, most scholars start by distinguishing them from related activities such as, play and games. Play, Guttman [7] viewed, may be spontaneous or organized. If it is organized, play becomes a game. Games, however, may be competitive or non-competitive. Competitive games, argues, Guttman [7], are contests, in turn can be divided into intellectual and physical contests. While sports have an intellectual component, fundamentally they are physical contests. Guttman [7] reached the conclusion that sports can be defined as organized contests of a playful, non-utilitarian character in which the physical demand overweigh the intellectual components. Berry McPherson et al (1989) provide a slightly different definition of sport in a slightly different term of its four basic criteria: Structured, Goal-oriented, competitive, ludic. Sports therefore are structured, goal-oriented, competitive forms of play. Finally, apart from the definitional outcomes, the anthropological domain focuses on sport as an aspect of culture, produced (socially constructed) by the participants but not always in the manner of their own choosing. Typical social and cultural studies of sport in the contemporary era have examined, among other things, sport subcultures, sport media, gender, racial, and international relations in sports, and more recently everything under the purview of globalization of sports

\section{Gender and Sports -Some Observations}

Gender refers to the socially constructed differences between women and men. It draws attention to the socially unequal distribution between femininity and masculinity. Studies of sports highlight the importance of distinguishing between gender and sex though the two concepts are used synonymously in everyday language and thought. Since the 1970s, research has demonstrated that sports are gendered social contexts in which, compared to girls and women, boys and men are more actively and enthusiastically encouraged to participate. Furthermore, it is demonstrated that more males than females participate in organized competitive sports and that male dominance characterizes the administration and training of sports, too. Associated with masculine imagery, sports serve to legitimize a perceived natural superiority of men and reinforce the inferiority of women, who are defined with reference to relative weakness, passivity and grace the characteristic of femininity. Therefore, sports have often been described as a 'male preserve' (Malcom, 2008:116). Social changes reflecting the condition of women in society influence the status of knowledge about the relationships between and within groups of women and men in sports. Since the 1970s, one consequence of feminist movement has been increased public awareness about the need for more opportunities for girls and women in sports. Subsequently, participation rates among some females increased at the regional, national and international sports events. These developments have resulted in ongoing challenges to gender stereotyping, resistance and negotiation of established gender ideology, and the initiation of important legal and political change regarding sex discrimination in sports and society. Hence, the new area of research on gender in sports has come of an age in anthropology and sociology, mainly. Feminist scholars from social and cultural anthropology and sociology have provided the most sustained attempts at conceptualizing and understanding gender in their studies of sports in culture.

Contemporary sports are truly global phenomena, bringing shared experiences to a worldwide audience - yet sports are not universally inclusive. Sports are considered the arena where traditional gender identities are constructed, reinforced, and contested [8]. The present article in a nutshell examines briefly the relationship between sports and gender. Its focus is on the 
anthropological significance of sports in contributing to the gender order. Finally, the article is concerned with how sports itself influence contemporary gender relations and also how sports can be used as a vehicle to challenge contemporary gender relations. Therefore, anthropological discourse views the women' under-representation in sports has a long history and is loosely associated with traditional views of gender relations. Historically, women have faced formal and informal restrictions on their sports participation, and played little role in the production of sports. Anthropological observations on the same milieu also depict that although social attitudes to men and women have become less restrictive, the modern female socialization (under the process of gender socialization) process continues to emphasize a form of femininity that gives little value to sports. At the beginning of the twenty-first century, women still occupy a marginal position in sports in virtually every country in the world.

Societal distinctiveness for females to be involved in sports is reinforced by resistance within the sports establishment. Men dominate all areas of sports provision including the sports media, creating a masculine ethos that pervades sports. Policies that promote gender equity within sports can face considerable resistance, and may be negated by the stronger forces of professionalization which characterize modern sports. The status of sports as a major social institution lends a special significance to women's subordinate position within it. Sports naturalizes differences between men and women as biologically determined and thus contributes to the construction of discriminatory gender relations. Addressing gender discrimination within sports offers to potential to challenge gender disadvantage as a whole [9].

\section{Concluding Interpretations}

It has been observed that sports are fundamental to the contemporary construction of gender differentiation. In an era when sport is established as a global phenomenon with a global appeal and audience, the impact of co-opting sports for males and excluding women from full sports citizenship is all the greater. The particular significance of sports, however, is not that it is unequally positioned to foster arguments that such difference is natural. The significance of sports in naturalizing gender difference, and thus legitimizing gender relations that privilege men over women, lies in the extent to which sports reinforce widely held assumptions that relationships of power between the sexes are based on "natural" or biological factors. Men's measurably superior performance in sports trials of strength and speed, and the construction of sports protocol around their physical attitudes in more complex game-codes, prove female inferiority. Sports, therefore, delivers apparently incontrovertible evidence of men's superior command of highly valued and visible skills, and by implication depicts females as less skilful, less capable and lesser value [10].

The particular power of sports in upholding gendered power relations lies in the looseness of sports to issues of men and women's embodiment and physicality. Sports, therefore, defines maleness as being in contrast to femaleness, and in this way makes a fundamental contribution to the construction of gender identities and gender relations that are based on assumptions of difference, which in turn perpetuate structures of disadvantage and exclusion. Over the last decades the growing recognition of women's marginalization in the sporting arena and men's continued dominance has led to an abundance of research focusing on the issue. Following the realization that most research into sports was produced by men and focused on the experiences of men, profeminist researchers responded by applying feminist theory, which was already receiving widespread use in mainstream sociology and cultural anthropology, to examine female experience and issues in sports. As the position of women in sports has changed so too has the type of feminist analysis that has been considered appropriate for examining women's experience. All approaches as well as studies have their critics and flaws, but all have also deepened understanding of women's experiences of sports [11,12].

Sports participation by women and girls is lower than participation by men and boys in virtually every country in the world. The differential between the sexes varies from country to country, and there are now a handful of countries in which the differences are only marginal. In most, however, they are marked and, in some cases, quite extreme. The overall pattern is unequivocal: females do not participate in sports on the same scale as males, and in most countries there is a wide gap between the sexes. Thus, women's relationship to contemporary sports is therefore a mixed picture. Comparisons with males appear discouraging, for there is little question that still, sports play a smaller part in women's lives than in men's, and appears less accessible to them. Seen over time, however, there is little doubt that this situation is changing. Women clearly gain a great deal of pleasure from sports participation, but their activities continue to be modified by feminine ideology. Women's entry into male sports is now tolerated, but only if it is accompanied by attitudes and behaviour that serve to normalize this deviant action and do not challenge male superiority within the sports. However, the mere entry is enough to redefine femininity and allow women to empower their bodies in what has previously been viewed as an exclusively male practice.

\section{References}

1. Haviland A (2002) Cultural anthropology. Wadsworth, USA.

2. Worthman, Carol M (1995) Hormones, sex, and gender. In: Durham W, Valentine Daniel E, Schieffelin B (Eds.), Annual review of anthropology. Stanford University Press, CA, USA.

3. Miller B (2011) Cultural anthropology. PHI Learning Private Limited, New Delhi, India.

4. Nanda S, Warms RL (2011) Cultural anthropology. Wadsworth, United States.

5. Jarvie G (2012) Sport, culture and society: An introduction. Routledge, London, UK.

6. Coakley J (2003) Sports in society: Issues and controversy. McGraw Hill, New York, USA.

7. Guttman A (1978) From ritual to record: The nature of modern sport. Columbia University Press, New York, USA.

8. Humerstone B (2002) Femininity, Masculinity and difference: What's wrong with a Sarong? In: Laker A (Ed.), The sociology of sport and physical education: An introductory reader. Routledge, London, UK. 
9. Kay T, Jeans R (2008) Women, sport and gender inequality. In: Houlihan B (Ed.), Sport and society: A student introduction. Sage Publications, London, UK.

10. Bryson L (1987) Sport and the maintenance of male Hegemony. Women's Studies International Forum 10(4): 349-360.
11. Blanchard K (1995) Anthropology of sports. Greenwood, New York, USA 12. Wag S (2009) Key concepts in sports studies. Sage, London, UK.

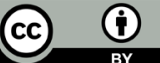

Creative Commons Attribution 4.0 International License

For possible submissions Click Here

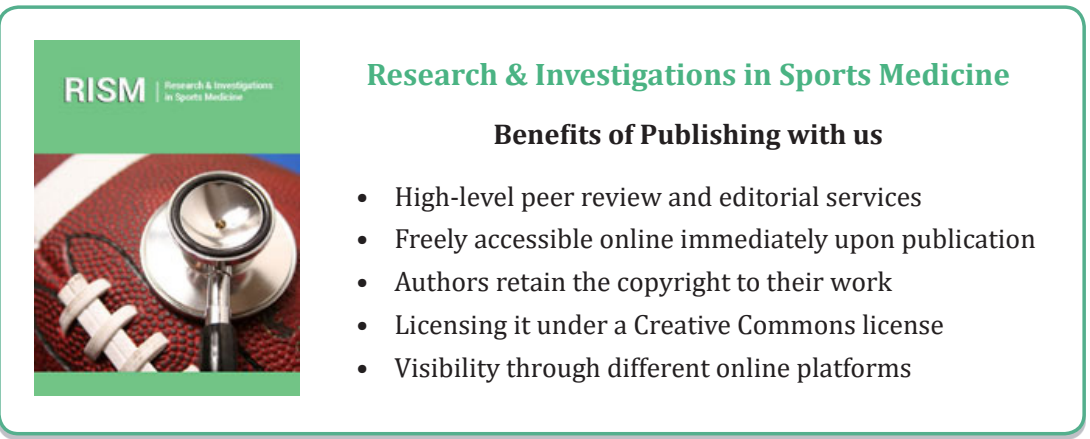

